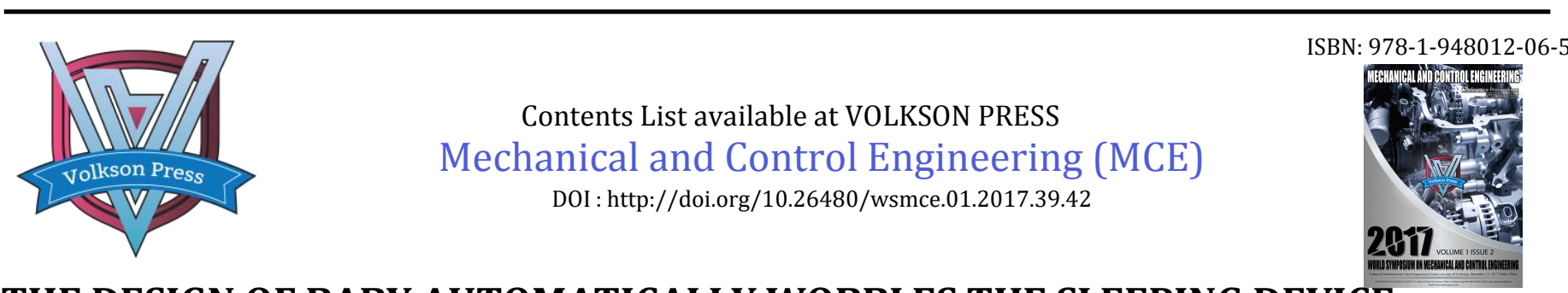

\title{
THE DESIGN OF BABY AUTOMATICALLY WOBBLES THE SLEEPING DEVICE
}

\author{
Li haixia, Linjican \\ Department of Mechanical and Control Engineering, GuiLin University of Technology, Yanshan District, Guilin City, China. \\ *Corresponding Author Email: 363039989@qq.com \\ This is an open access article distributed under the Creative Commons Attribution License, which permits unrestricted use, distribution, and reproduction in \\ any medium, provided the original work is properly cited
}

\section{ARTICLE DETAILS}

\section{Article History:}

Received 02 october 2017 Accepted 06 october 2017 Available online 11 november 2017

Keywords:

Automatic baby shake sleep

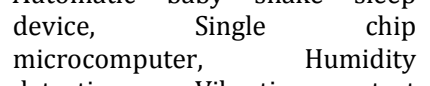
detection, Vibration test

\section{ABSTRACT}

In twenty-first Century, people's living demand is higher and higher, the SCM application is more and more widespread, and the residents' equipment is constantly intelligent, in which the baby automatic rocking sleep device is a manifestation. For understanding the modern city infant care needs, combined with the development situation both at home and abroad, this paper puts forward a design of intelligent nursing device for baby, analysis device is feasible in theory, through the analysis of the process of care and infant care personnel needs, will demand into the design language, so as to establish the functional framework of infant nursing device, MCU minimum system as the basis, structures of each module, design a baby care device model, so as to assist the care function, ease the pressure on the role of guardian care of infants. The main purpose of this design is to study the diversification of the baby bed, and design a control unit based on single chip microcomputer. The baby bed takes the smallest system of STC89C51 as the main control unit. The external temperature and humidity detection module, the voice sensor detects the baby's crying, and uses the buzzer to play music.

\section{Introduction}

\subsection{Background}

The automatic rocking sleep device is a automatic furniture that has a variety of functions, which is a mechanized and automatic research field of a family. In the modern era of intelligence, people continue to research and develop various intelligent machines, not only provide efficient and comfortable services for mankind, but also promote the progress of human civilization [1]. Compared to traditional cribs, the baby's automatic rocking sleep device is designed to have more intelligent functions, for example, according to the baby is asleep or no to control the swing and play a lullaby, when the baby diaper package not good cause to leak alarm. This kind of intelligent furniture developed countries already have a wide market in foreign countries especially, but the technology is not mature enough Chinese, further research and development of automatic rocking sleep equipment for infants is of great significance [2].

\subsection{Development status at home and abroad}

Traditional Chinese shaking bed is a commercial design, so the lack of people-oriented concept [3]. As mentioned earlier, this shaking bed is very unfavorable for the baby, baby will feel unsafe, uncomfortable, it will lead to not fall asleep quickly, this is likely to cause a vicious cycle: parents would think is no enough to shake then intensify shaking bed, bring more serious harm to the baby. In some developed countries such as Europe and the United States, they will think that the Chinese traditional shake bed is not a kind of humanized even harmful to the baby, even some people think that use this shake bed to the baby is in abuse baby! In the face of this failed industrial design, why it can be so popular at home, investigate its reason, a portion of the domestic producers are focus on one's own interests, for the sake of profiteering, they just mix the crib with the cradle, thus creating an illusion that prices are both cheap and high-performance price ratio to deceive consumers [4-7]. Manufacturers try their best to publicity their products with Low price and Multi-function, no matter the shake bed whether or not qualified or beneficial for the healthy growth of the baby. In the case of consumers' unawareness, their sales have been successful, put this inferior quality has been turned into a hot sale product. As we don't know, this low price, cost-effective, popular with young Chinese parent's welcome products, has hurt our tens of thousands of the next generation, and this situation is still continuing artificially....... According to some statistics, in China, babies born with cradle syndrome are up to 5 percent, while in the United States, only 5 percent are [8].

\subsection{The main content}

The main content of this design is to design a baby automatic shaking device. STC89C51 series microcontroller minimum system as the core, temperature sensor DS18B20 test the ambient temperature of the infant, preventing the temperature from overheating and affecting the infant, the humidity sensor senses whether the baby has urine, voice sensor to detect whether the baby is crying, the MCU to detect information, the corresponding output signal to the actuator [9]. The general work can be divided into three steps: hardware design, software programming and debugging:

(1) System hardware design. Based on the minimum system of STC89C51 single chip microcomputer, the peripheral circuit is built according to each module circuit.

(2) Write the driver of each module. Design and control the program according to the designed hardware structure of the shaking device of the baby bed and the control principle of the control principle.

(3) System debugging. First, the system is tested and the software function test, and then the whole system is debugged, including the update of attitude data and the setting of sensor sensitivity.

\section{HARDWARE DESIGN}

\subsection{System structure of baby automatic rocking sleep device}

Automatic rocking device for baby sleep by the control unit, detection unit, driving unit, the bed body is composed of four parts, detection unit, driving unit and control unit are connected by wires and arranged on the bed body in different positions, with convenient manipulation, embodies the practical [10.]. The humidity sensor placed below the sleeping plate in infants, to facilitate the detection of sleep in humidity, LED lamp on the bed body conspicuous position for observation, its structure is shown in Figure 


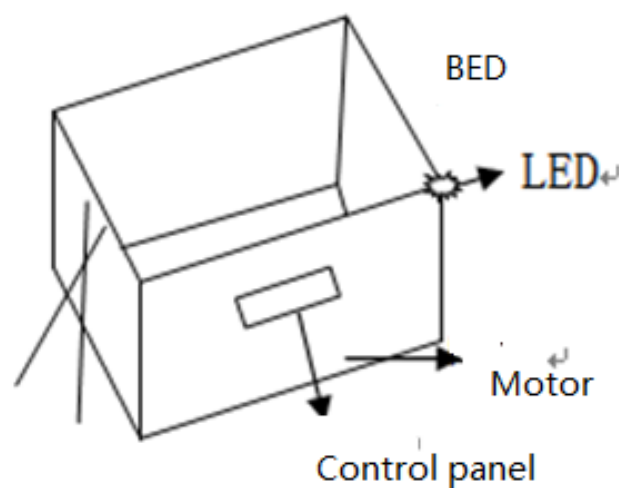

Figure 1: Crib structure drawing

Considering the factors of cost and time, this design does not design the frame of the bed, and only uses the motor rotation to represent the bed.

\subsection{Control scheme}

The automatic rocking sleep device for infants is composed of three inputs and three outputs. The input part is humidity detection and temperature detection, and the voice detection is output, and the output part is a buzzer drive, a motor drive and a display module [11]. The initial state LCD shows the current temperature, the setting temperature, and the motor speed. The transmission module adopts 5V DC motor driven simulation, because of very low pin output current cannot drive DC motor rotation, so the need for external drives, DC motor driven by the driver L298N, when the microcontroller given signal to drive DC motor will do the corresponding action [12]. The humidity sensor collects the humidity of the baby bed cloth, the SCM processes the received digital signals, makes corresponding alarm actions, and displays the word "WET" on the LCD. The voice sensor detects the baby's crying, and processes the output signal through the SCM to drive the motor to rotate and play the music. The alarm buzzer is driven by a triode to realize the alarm function. Use LM393 to drive speakers and play music.

\subsection{Hardware system diagram}

The design of the system diagram as shown in Figure 2, the control module diagram to STC89C51 microcontroller as the core of the controller, the hardware circuit mainly includes motion detection module, humidity detection module, motor drive module, alarm module, music playback module, man-machine communication by key module, alarm module, can realize the startup device, show the humidity condition of the bed cloth. The Humidity controller drives the LED alarm through the program logic, drive buzzer plays hypnotic music. The software part of the application MCU C language design, including detection module subprogram, motor driver module subroutine, and alarm, music playback driver [13].

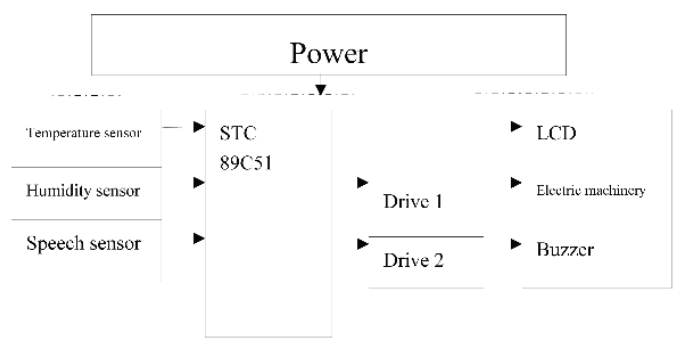

Figure 2: Hardware system diagram

Humidity detection of two separate copper pieces, connected to a A-D conversion module, the module pin is simple, only a data line, the system is simple, you can put in the bed. The output form has analog voltage output and digital switch output. It meets the demand of this design. When the bed cloth is wet, the SCM will send out the corresponding alarm action. When the sleeping baby cries, the sound sensor collects the signal and outputs the signal to the SCM, and the output signal of the single chip drives the motor to rotate and play the music so that the baby can fall asleep as soon as possible.
The design check module uses DS18B20, a digital temperature sensor manufactured by Dallas semiconductor, is the world's first temperature sensor supporting the 1-wire bus interface, in its internal use, the board (ON-BOARD) patented technology [11]. All sensor components and conversion circuits are integrated into an integrated circuit shaped like a triode. The unique and economical characteristics of the 1-wire bus enable users to easily build sensor networks and introduce new concepts for the construction of measurement systems. Now, the new generation of DS18B20 is smaller, more economical, and more flexible. The advantage of "one wire bus" can be brought into play [14].

\subsection{Baby cry detection module}

\subsubsection{Module description}

The company's VB100 baby cry detection module is aimed at train and identification when baby crying at the age of $0-2$. Only when the baby cries, this module will recognize then trigger and send out signals. Other external devices can be processed after that [15]. In the market, generally known as the "baby cry detection" products, actually does not have the true recognition function, only for the intensity of sound detection, any sudden bursts of sound, such as the telephone, take applause, adult voice will trigger.

Sound company VB100 products, to distinguish between crying and background noise. Researchers draw sound on the company hundreds of the age $0-2$, different gender and race the child crying, and music, traffic noise and other interference environment cry, even include the venue for hundreds of speakers. The detection of other environmental sound shielding only detected baby cry. This module can be installed in the crib, children's room, and the stroller.

2.6.2 Module of product development and development company based on manufacturers, according to the characteristics of their products, can be connected with the electronic devices of different modules in the backend, the formation of different products, applications of this module may include:

a. once detected crying, you can play a parent recorded sound to comfort the baby.

b. the detection of crying, you can trigger some other sound light toys, distract the baby's attention.

c. when the cry lasts for a certain period of time, or in a certain period of time for several consecutive cry, then with text messages, micro-blog, telephone, open the intercom, e-mail and other different ways to inform parents.

d. or statistics on the number of babies crying during sleep and intervals, as the baby's health record.

The cry detection module will bring more practical electronic products to parents in the new age.

\subsection{Buzzer}

Because the output current of SCM pin is very small, the buzzer and LED cannot be operated, and the triode is used to enlarge the output current of the microcontroller pin, and the power is switched off at the same time [16]. To make the alarm more obvious, LED uses red. The use of active buzzer, a piezoelectric buzzer buzzer and two types of the buzzer, its working principle is when the current through the solenoid coil, the electromagnetic coil generates a magnetic field to drive the vibration film sound, therefore requires a certain current to work properly. While the microcontroller pin output current is too small, so that they cannot drive the buzzer, and amplify the current through the transistor, the current reaches the current value of the buzzer can work at the same time, through the transistor on-off control buzzer and stop [14]. The buzzer driver circuit is shown in figure 3-9

\subsection{Noise treatment}

In the motor rotation, buzzer alarm, it will produce noise, easy to scare the baby, counterproductive, so it is necessary to deal with noise, improve product comfort, practicality.

\subsubsection{Motor noise treatment}

The motor and the bed body to form a whole, so the motor and the bed body cannot be isolated, must choose the type of motor, using high-speed 
mute brushless DC motor can effectively reduce the noise of the motor, this motor of small size, high speed, high power, low loss, high reliability, low noise, high efficiency, speed wide range, high torque, self adaptation series, Aluminum Alloy housing complex environment.

\subsubsection{Alarm noise treatment}

Detect the baby crying, baby bed wetting and environmental temperature is too low, the buzzer will alarm, but if the baby is in a sleeping state, the alarm will disturb the baby [17]. In order to solve this problem, use LED to replace the buzzer lamp design, at the same time beside LED in parallel with a wireless module, the alarm signal will be transmitted to the parent control room, the receiver is installed in the control room, with a buzzer alarm, so that it can be separated from the alarm with the baby. Because the wireless transmission function design cost is high, the work load is big, plus my ability is limited, the wireless function has not manifested in the physical object, but is still feasible [16].

\subsection{Human-computer interaction module}

The human-computer interaction module on the control panel includes buttons, buzzer, and LCD display. The smallest single-chip system comes with two buttons, one is with a self-locking switch, you can start and stop work is a microcontroller, other button is MCU reset pin point switch, press, microcontroller RST received two cycles of high level, can make the MCU reset [18]. In the input module access self-locking switch, can be artificially controlled detection or not, similarly, in the motor drive module access self-locking switch, can artificially select motor rotation or not, more personalized $[19,20]$.

\section{SOFTWARE DESIGN}

The main idea of this design is to complete the design of the hardware first, according to the schematic diagram of the circuit, complete the program design of the software part from the function and requirement that it wants to realize. This design uses $\mathrm{C}$ language programming, because compared with assembly, in function - structure - readability maintainability $\mathrm{C}$ language has great advantages, very practical. With the idea of modular programming, this method is easy to master and realize. The system will be programmed into several modules, mainly:

a. humidity sound detection module;

b. drive;

c. display module;

d. keyboard module and other modules;

e. buzzer driver module

\subsection{Master program flow chart}

The design works of the work flow is: when the system starts to complete the initialization, each module initialization state, LCD displays the current temperature and the preset temperature, the motor speed; when it is detected that the baby crying, began to play music, and motor rotation $5 \mathrm{~S}$, LCD display "cry"; when the detected bed wetting, The buzzer alarm, LCD display "wet", and the buzzer alarm; when the ambient temperature is lower than the set value, the buzzer alarm and LCD display "cold" [17]. The main program flow chart is shown in figure 3.

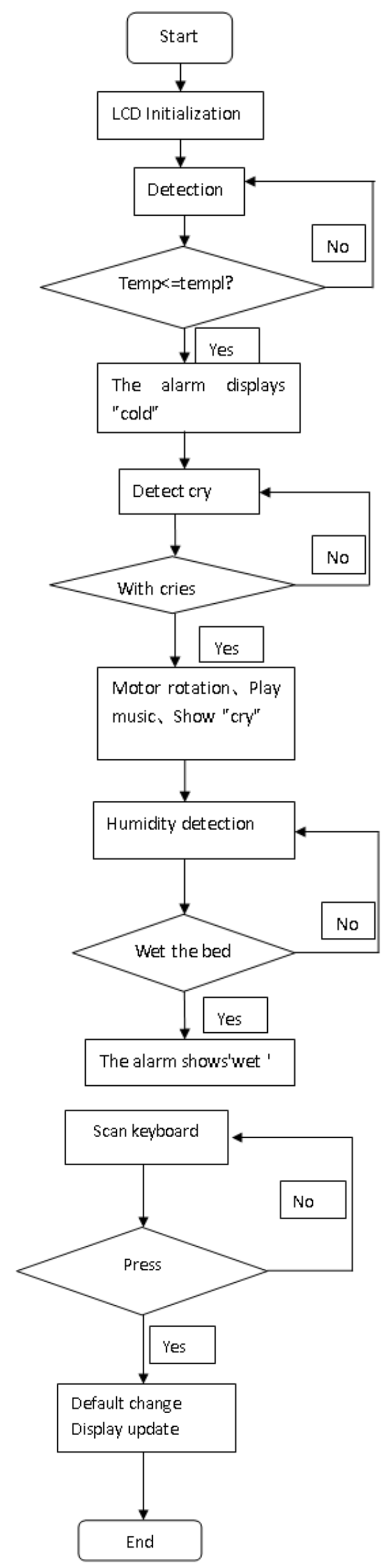

Figure 3: Flow chart of main program 


\subsection{Display subroutine}

Display update subroutine: initial status LCD shows current temperature, preset temperature and motor speed. The display program flow is shown in Figure 4

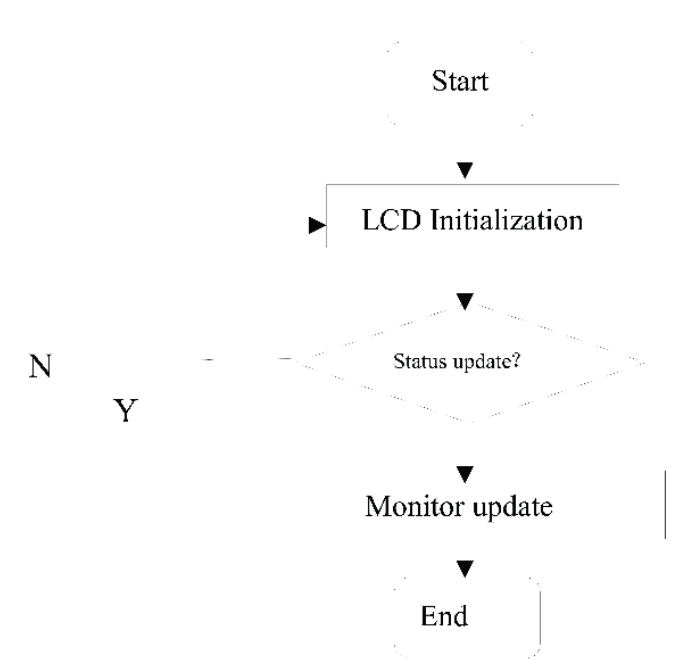

Figure 4: Shows the program flow chart

3.3

Temperature detection program

The temperature is too low, the baby bed wetting will trigger the alarm, if the ambient temperature is lower than the preset temperature, the buzzer alarm will sound, the baby bed wetting, the sensor detects humidity after the buzzer will alarm sound; when the baby cries, the sound sensor trigger high level then motor starts to rotate, the horn to play music.

\section{SYSTEM DEBUGGING}

After hardware production, debugging, to achieve the required functions.

\section{Acknowledgement}

This work is supported by 2017 Guangxi Zhuang Autonomous Region In The Young Teachers Basic Ability To Enhance The Project (2017KY0271)

\section{REFERENCE}

[1] http://home.babytree.com/u342341450/journal/show/2486 $\underline{640}$

[2] Haisong, C. 2012. A practical tutorial on application skills of single chip microcomputer [M]. Beijing: Publishing House of electronics industry.
[3] Ying, C., Sibai, T. 2006. Analog electronic technology (Fourth Edition) [M]. Beijing: Higher Education Press,2006.

[4] Hong, H. 2006. editor. Principle and interface technology of single chip microcomputer. Nationa Defence Industry Press.

[5] http://max.book118.com/html/2012/1106/3189948.shtm

[6] Fujun, L. 2012. Automation technology and application, [J]. Thirty-eighth Research Institute of China Electronic Science and technology group.

[7] Guang, L. 1999. No.1.SCM Foundation (First Edition) [M]. Beijing: Bei Hang University press.

[8] Jun, L. 2011. An example said STM32 [M]. Beijing: Beihang University press.

[9] Yuying, L. 2010. Modern electronic technology School of information, Donghua University[J].

[10] Feng, M.L., Qiu, W.Y. 2009. Single-chip principle to interface technology (third edition) [M] Beijing: Tsinghua University Press.

[11] Yi, R., Boshi, C. Electric drive automatic control system (Fourth Edition) [M].Beijing: Mechanical Industry Press.

[12] Li, S.Y., Wu, S. 2016. Sensors and measurement technology[M]. Anhui: HeFei University of Technology press.

[13] Diandong, X., Zhijun, X. 2003. Practical Handbook of digital circuit design [M]. Beijing: Publishing House of electronics industry.

[14] Yang, Y. 2006. A concise tutorial of analog electronic technology [M]. Beijing: Higher Education Press.

[15] Fuxue, Z., Shen. 1992. Application of sensors and circuit selection [M]. Beijing: Publishing House of electronics industry.

[16] Zhigang, H., Zhihe, Z. 2013. Electronic world [J]. Jiangsu Feng Feng senior high school.

[17] Haoqiang, T. 2010. C programming tutorial [M]. Beijing:Tsinghua University press.

[18] Bin, W.P. 2016. Interface and application of single chip microcomputer [M]. Beijing: Metallurgical Industry Press.

[19] Honglin, Y., Mingming, L., Bingbin, B., Xiang, Z. 2016. Wireless interconnection technology [J]. Jiaxing, Career Academy.

[20] Tianpeng, Z., Lei, X. 2011. Industrial design [J]. School of engineering, Beijing Forestry University. 